\title{
Exploring the Determinants of Internet Usage in Nigeria: A Micro-spatial Approach
}

\author{
Kayode Odusanya $^{1(\bowtie)}$ (D) and Morakinyo Adetutu ${ }^{2}$ \\ ${ }^{1}$ School of Business and Economics, Loughborough University, \\ Loughborough, UK \\ k. odusanya@lboro.ac.uk \\ ${ }^{2}$ Centre for Sustainable Development, Warwick University, Coventry, UK
}

\begin{abstract}
The dearth of Information Communication Technology (ICT) infrastructure in the Sub-Saharan Africa region underscores the argument that the spread of broadband infrastructure can foster internet adoption in the region. Consequently, the aim of this paper is to present results on the determinants of internet adoption in a sub-Saharan African country. Drawing on a dataset of households in Nigeria, this study presents findings on the demographic, socioeconomic and infrastructure factors that predict internet usage in Nigeria. The novelty of our analysis stems from a unique dataset constructed by matching geo-referenced information from an inventory of network equipment to a nationally representative street-level survey of over 20,000 Nigerians, by far one of the largest technology adoption surveys in sub-Saharan Africa to date within the information systems literature. The results are discussed and concluding remarks highlighting next steps are made.
\end{abstract}

Keywords: Internet usage $\cdot$ Broadband $\cdot$ Socio-economic determinants · Technology diffusion $\cdot$ Micro-spatial approach

\section{Introduction}

Internet access is perhaps one of the most significant indicators of human and socioeconomic development. It fosters productivity and innovation (Avgerou 2008; Paunov and Rollo 2016), social interactions (Liang and Guo 2015) and reduces communication and search costs (Beard et al. 2012). Yet, there is a digital divide in the level of internet access among developing countries, especially those in sub-Saharan Africa (SSA) compared to the rest of the world. Within SSA, the lack of internet access is a recognized barrier to the adoption of information communication technologies (ICTs) (Afolayan et al. 2015). This argument seems to be supported by regional broadband statistics, as shown in Fig. 1 where SSA is portrayed to have the lowest levels of internet penetration and wireless broadband infrastructure per capita, relative to other regions of the world. While previous studies have shed light on the regional variation in internet adoption by focusing on the determinants of internet penetration in the context of the "digital divide" (e.g. Oyelaran-Oyeyinka and Lal 2005; Chinn and Fairlie 2010), these studies often employ infrastructure measures/proxies (such as fixed telephone lines per sq. km, main telephone lines per capita, etc.,) thereby overlooking the peculiar 
nature of broadband infrastructure in the SSA region. More specifically, we note that internet use across the SSA region is undertaken mainly via wireless broadband access, rather than fixed-line broadband. Thus, in this paper, we draw on a unique dataset that combines geo-referenced (longitude and latitude) information on 3G and 4G wireless network equipment to examine factors that predict of internet usage in Nigeria - a subSaharan country. Consequently, this study offers two potential contributions to the literature.

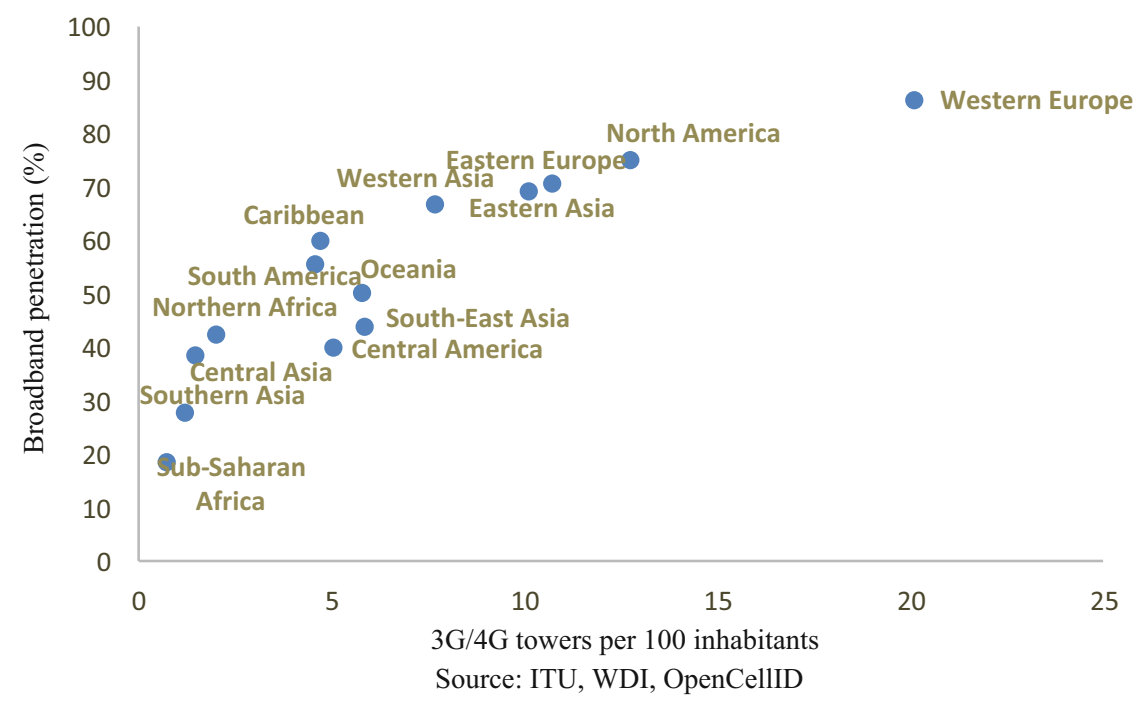

Fig. 1. Internet penetration and broadband infrastructure, 2017

First, unlike previous studies, we demonstrate a measure of broadband infrastructure is micro-spatial in nature, i.e., it is based on the density or concentration of $3 \mathrm{G}$ and $4 \mathrm{G}$ equipment around each household's dwelling over specified spatial domains. To achieve this, we match street-level information from the technology survey to the Global Positioning System (GPS) coordinates of 3G and 4G cell towers. This microspatial approach renders more nuanced and invaluable insights on whether/how spatial proximity or access to wireless internet connection shapes adoption decisions at the local level. Afterall, without connectivity, it is practically impossible to adopt/use broadband services. Furthermore, this spatial approach also embodies the reality that signal quality, a key determinant of actual usage behaviour, is shaped by the physical proximity of users to broadband connections (Neto et al. 2005; DeStefano et al. 2018). Hence, in addition to treating the spatial diffusion of wireless network infrastructure as an appropriate measure of broadband infrastructure, it is also a quality-weighted indicator that enriches our analysis.

Second, our focus on Nigeria provides a plausible and timely case study of the effect of broadband infrastructure diffusion on internet usage in SSA and the broader developing country context. Given that it accounts for the largest proportion (18\%) of 
the entire SSA region's 1.03 billion population (World Development Indicators, 2018), we would argue that Nigeria is the most representative country of the SSA region. Furthermore, ITU estimates indicate that more than $90 \%$ of the youth population in developed countries use the internet compared to $30 \%$ in less developed regions of the world. Considering that the proportion of Nigeria's population below 40 years is projected to reach $81 \%$ by 2030 , broadband penetration is likely to have a significant role in shaping Nigeria's participation in an increasingly digitalized future economy. Finally, despite growing to become Africa's largest economy and one of the major emerging economies in the world, Nigeria epitomizes the co-existing low levels of internet penetration and ICT infrastructure deficit (The Economist 2016). The remainder of this paper is organized as follows. In Sect. 2, we undertake a critical review of related literature on internet adoption and ICT infrastructure. This is followed by the model specification and the methods section. In Sect. 5, we discuss the results and conclude in Sect. 6 highlighting next steps and expected contributions of our study to the information systems literature and policy.

\section{Related Literature}

The literature on internet adoption and penetration is large. Consequently, due to space constraints, the goal of this review is not to present an extensive discussion of existing literature. Rather, we highlight a gap in the use of proxy measures in accounting for technology adoption. A more comprehensive review can be found in Cardona et al. (2013).

A dominant strand in the literature pertains to cross-country studies aimed at evaluating the determinants of internet usage and penetration in the context of the digital divide in developing countries. One of such studies is Dasgupta et al. (2005) who investigated the determinants of internet intensity (internet subscriptions per telephone mainline) for a cross country sample of 44 OECD and developed countries. Similarly, Chinn and Fairlie (2007) provide an analysis of internet penetration using a larger sample of based on panel data for 161 countries over the 1999-2001 period. They control for a range of macro-level determinants on telecoms prices, per capita income, education, age structure, urbanization, regulatory environment, etc. Although this study also controls for ICT infrastructure, their reliance on telephone density may not be applicable to the African context. Other internet diffusion/penetration studies use large cross-country samples from developing regions of the world (e.g. Chinn and Fairlie 2010). A few studies however focus on internet penetration for more specific sub-groups/regions of the world such as OECD (Lin and Wu 2013), The Americas (Galperin and Ruzzier 2013), APEC (Liu and San 2006), Africa (Oyelaran-Oyeyinka and Lal 2005) and Asia (Feng 2015). Greenstein and Spiller (1995) investigate the impact of telecommunication infrastructure (measured by the amount of fiber-optic cables employed by local exchange telephone companies) on economic growth in the U.S. Roller and Waverman (2001) investigate the linkages between broadband investment and economic growth across 21 OECD countries and 14 developing countries during 1970 to 1990 . More recent studies have focused specifically on the impact of broadband infrastructure. For instance, Czernich et al. (2011) investigated the 
effect of broadband infrastructure on the economic growth for a panel of OECD countries over the period 1996-2007. However, they model this relationship by analyzing how broadband infrastructure (proxied by broadband penetration) shifts the growth parameter of technological progress within a macroeconomic production function setting. Tranos (2012) explored the causal effect of broadband infrastructure (internet backbone capacity) on the economic development across European city regions over the period 2001-2006 with ICT infrastructure found to stimulate economic development.

Three important observation can be gleaned from the above literature review. First, the cross-country studies tend to focus on the digital divide, attempting to explain internet adoption and penetration based on changes in economic, social, demographic and regulatory/institutional factors. Even when these studies attempt to account for the role of telecoms infrastructure, they do so by using variables such as personal computers per 100 people, main telephone lines per 100 people, customers' equipment (e.g. telephone set, facsimile machine), etc. Second, studies based on microdata tend to focus on developed country contexts, while also relying on infrastructure proxies that are analogous to the cross-country studies. Moreover, the developing country studies are not free from this problem too. Third, even studies that focus mainly on the effect of ICT infrastructure on economic measures and internet adoption also employ similar ICT infrastructure measures such as investments in telephone/broadband cables.

In comparison to the cited studies, we take a different approach by employing a true measure of internet infrastructure that is based on the prevalence of wireless network equipment (i.e. towers and radios). We then explore the effect of wireless network access on internet adoption at the individual level, based on physical proximity to broadband connection. Research has shown that variations in technology adoption are shaped by heterogeneity in geographical network access, such that the physical proximity to broadband connection or infrastructure can be expected to shape adoption decisions at the local level. For instance, it is well established that urban areas benefit from higher concentration of ICT infrastructure, which may enable social learning and adoption of ICT technologies (Liu and San 2006). Hence, unless this type of analysis is undertaken, these disparities in network access may be inadvertently explained away as differences across individual income or demographic characteristics.

This paper is also related to a small and evolving body of studies that exploit spatial data towards analyzing the diffusion of telecommunications technologies. Our review shows that research conducted by Buys et al. (2009) and Hodler and Raschky (2017) come close to the line of inquiry pursued in this study. However, they differ significantly from this study in two crucial ways. Firstly, both studies conduct country-level spatial analysis while we adopt a micro-level spatial approach. Secondly, while the former investigates the determinants of mobile operators' spatial location of network sites across Sub-Saharan Africa, the latter explores the role of ethnic politics in shaping the spatial diffusion of mobile phone infrastructure in Africa. As far as we know, the closest relative to this study is DeStefano et al. (2018) where the authors investigated how the arrival of ADSL broadband technology influenced the IT-productivity gap among UK firms. Comparatively, this study is therefore the first to explore the individual-level influence of broadband infrastructure on internet adoption using a micro-spatial approach, especially in a developing country context. 


\section{Model Specification}

This study uses a probit model to examine the determinants of internet usage in Nigeria. Probit models are used when the dependent variable is dichotomous. We employ a set of explanatory variables in our model, namely: demographic factors include age, gender, marital status and religious affiliation; socio-economic factors such as expenditure, education, whether they are employed or not and a location variable indicating whether respondents live in rural or urban areas. Finally, we also include a micro-spatial infrastructure representing the number of internet infrastructure within a radius of where they live (i.e. towers) and the average tariff per megabyte of data used (tariff). Both towers and tariffs represent our infrastructure variables included in our model. Thus, our model is represented by the equation: Internet Use = $\mathrm{f}$ (age, gender, income and education, marital status, religious affiliation, towers, tariffs, urban).

We expect monthly expenditures (our proxy for income) to affect broadband adoption/usage positively. The probability of this adoption decision is also likely to rise for more educated individuals. However, the need for possessing an internet subscription, however, may fall for older and unemployed respondents. In terms of age, one could argue that, whereas younger individuals may have lower income, they tend to demonstrate a greater degree of technological affinity (Hübler and Hartje 2016). We add a gender variable as an additional characteristic, given that the preferences and decisions of men are more dominant than the preferences of their spouse(s) in patriarchal societies (Bulte et al. 2016). Similar considerations can be extended to the marital status of an individual on the adoption of internet technologies. Finally, technology adoption decisions are often shaped by religious reasons, as some religious beliefs may restrict the adoption of conventional technological products (Fungáčová, et al. 2017). Hence, we control for the religious beliefs of each sampled individual.

To examine the effect of broadband infrastructure on internet adoption, used a measure that captures individual-level access to wireless broadband network. Hence, we employ a microspatial variable that captures the prevalence of wireless network infrastructure at the individual level. We calculate this variable using information from our two data sources in four steps. First, inspired by Hodler and Raschky (2017), we extract and map the $3 \mathrm{G}$ and $4 \mathrm{G}$ cell tower locations from OpenCellID (see Fig. B in the appendix section). Secondly, we extract and map the street-level dwelling locations from the survey data. Thirdly, to use both data for our purpose, we link them by overlaying the towers map with the dwelling location map. Finally, we compute a micro-spatial infrastructure variable as the total number of cell towers within $5-\mathrm{km}$ radius of everyone. This $5-\mathrm{km}$ specification is premised on the fact that network coverage in SSA is mainly based on base stations that can provide service up to a 5-10$\mathrm{km}$ radius (Aker and Mbiti 2010, p. 209). We achieve this using the Stata 'spmap' command.

\footnotetext{
${ }^{1}$ See https://www.stata.com/support/faqs/graphics/spmap-and-maps/ for resources on the spmap command.
} 


\section{Method}

\subsection{Data Collection}

To investigate the effect of wireless connectivity on internet usage, we rely on a unique nationally representative market survey of Nigeria carried out by Africa's largest mobile operator, MTN $^{2}$ during April-July 2018. The MTN survey, which covers 730 localities (i.e., villages or towns), is by far and away one of the largest and most comprehensive technology surveys in sub-Saharan Africa to date. The data was collected via the use of paper questionnaire distributed to respondents in all 36 states of the country. Figure A in the appendix section plots the centroid GPS coordinates of surveyed areas at the municipality level. The wide geographical spread of the survey areas confirms the nationally representative nature of the survey. A total number of 21,844 observations were obtained for the final analysis. Our second data resource is the OpenCellID database which contains information on the micro-spatial independent variable (towers). The database contains raw information on the geo-location (longitude and latitude) of around seven million unique cell sites across the world (Hodler and Raschky 2017). One key benefit of the OpenCellID database is the possibility to identify the technology (radio) type for each telecommunications tower (i.e. GSM, UMTS, LTE, etc.). This allowed us to identify the two wireless network classes: "UMTS" (third-generation technology, 3G) and the more advanced "LTE" (fourthgeneration technology, 4G) types. Specifically, we identified a total of 13246 unique tower locations from the OpenCellID data consisting of $114703 \mathrm{G}$ and $17764 \mathrm{G}$ sites. These sites are geo-coded at the GPS (longitude and latitude) - level (see Fig. B in the appendix).

\subsection{Measures}

Our main dependent variable is represented by a broadband usage variable for the use of broadband services. To construct this indicator variable, we convert survey responses on broadband subscription using the question: "Which of the following telecommunication services ${ }^{3}$ do you use nowadays?". We then calculate the dependent indicator variable as a dummy that takes the value " 1 " if "Data service (Accessing internet)" was selected in response to the question. Otherwise, a dummy value of " 0 " was assigned to the observation. Table 1 provides the summary statistics of the variables employed in this study. The internet adoption rate within our dataset is $12 \%$, falling firmly within the same ballpark as the $13.7 \%$ and $15.2 \%$ broadband penetration rates reported by Business Monitor International (BMI 2018) and the ITU, respectively. The summary statistics in Table 1 also indicate that there are on average 28 wireless network towers within $5 \mathrm{~km}$ of each respondent's street. However, the standard

\footnotetext{
${ }^{2} \mathrm{https}: / / \mathrm{www} . \mathrm{mtn} . c o m / \mathrm{MTN}$ is the market leader in the Nigerian telecoms industry, accounting for $40 \%$ market share. See statutory regulatory data at https://www.ncc.gov.ng/stakeholder/statisticsreports/industry-overview.

${ }^{3}$ The listed service options include "Voice services", "Data service (Accessing internet)" and "Digital/2G services".
} 
deviation of 40 towers within the $5 \mathrm{~km}$ radius suggests a reasonable spread or dispersion of the cell tower variable.

Table 1. Summary statistics of variables employed

\begin{tabular}{l|r|c}
\hline Variable & \multicolumn{1}{|l|}{ Mean } & Standard deviation \\
\hline Internet adoption & 0.119 & 0.324 \\
\hline Internet infrastructure & 28.075 & 40.016 \\
\hline Expenditure $^{\mathrm{a}}$ & 55055.25 & 79552.62 \\
\hline Tariffs & 0.627 & 0.088 \\
\hline Age & 43.974 & 18.394 \\
\hline Education & 13.314 & 4.978 \\
\hline Male & 0.561 & 0.496 \\
\hline Married & 0.624 & 0.484 \\
\hline Unemployed & 0.118 & 0.323 \\
\hline Christian & 0.619 & 0.486
\end{tabular}

Note: Internet infrastructure: $3 \mathrm{G} / 4 \mathrm{G}$ towers within $5 \mathrm{~km}$ of respondent; Expenditure: sum of expenditures on food, rent, fuel, clothing \& healthcare; Age: age of the individual in years; Education: no of years of formal education; Male: Dummy $=1$ if individual's gender is male; Married: Dummy $=1$ if individual is married; Unemployed: Dummy $=1$ if individual is unemployed; Christian: Dummy $=1$ if individual's religion is Christianity; Tariffs: average tariff per megabyte (MB) of data use. Number of individuals: 21844

${ }^{a}$ Expenditure is in Nigerian Naira (1 Nigerian Naira $=£ 0.0022-$ as at 14 November 2019)

\section{Results}

Table 2 presents the marginal effects from baseline probit estimations. In column 1, we start by measuring the network infrastructure effects on broadband adoption: probability of adopting internet services, without any control variables or locality effects. Due to the cross-sectional nature of our data, we interpret these results as associations. It is clear from the results in columns (1) that a strong positive correlation exists between the concentration of broadband infrastructure around each individual and internet adoption. This coefficient is significant at the $1 \%$ level. From column 2 to 10 , we add the control variables one by one, but the infrastructure coefficient remains statistically significant at the $1 \%$ level, albeit the magnitude of the coefficient drops. In column 11, we include locality effects to draw inference only from the variation in individual adoption decisions. Besides employing controls and locality effects, we use heteroskedasticity-robust standard errors clustered at the locality level that allow the data to be independent across localities by restricting the error terms to be correlated for individuals within the same areas on account of omitted regional characteristics. 
*

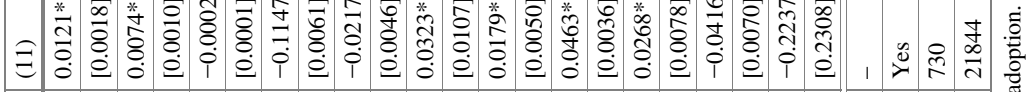

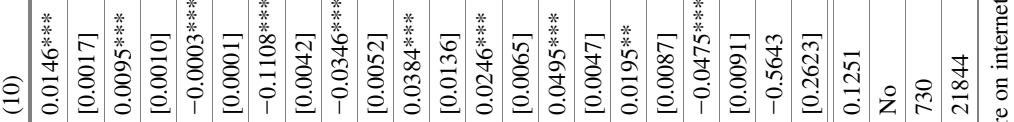

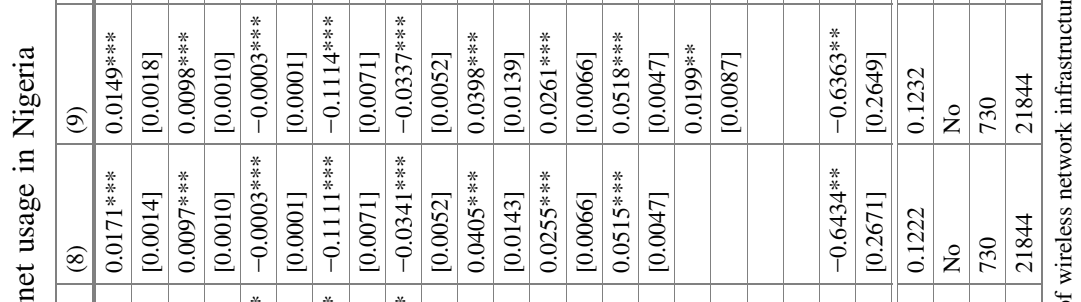

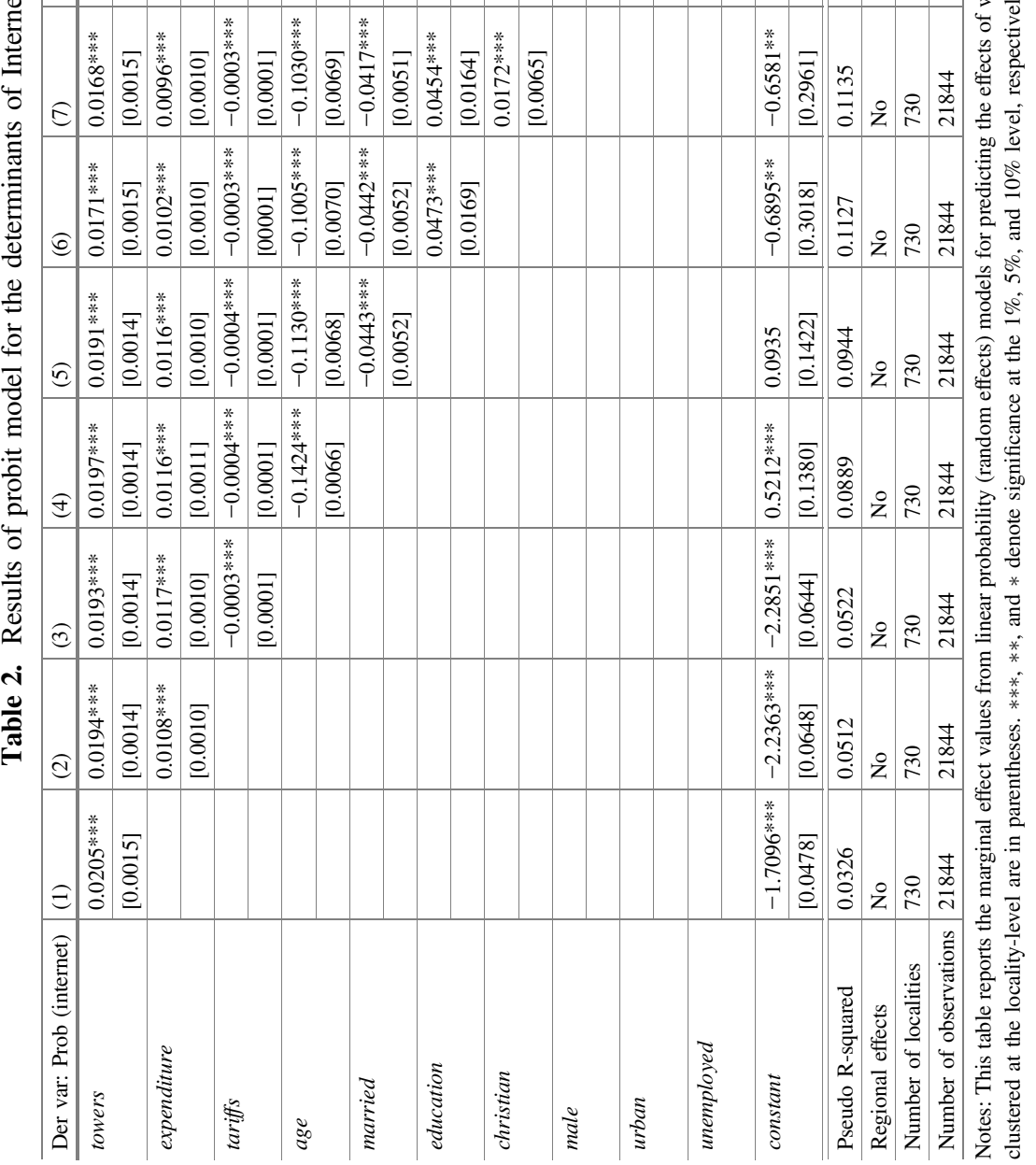


As seen in Column 11, the infrastructure coefficient retains its statistical significance but drops further. Specifically, infrastructure coefficient of 0.012 suggests that a unit increase in the number of cell towers within $5 \mathrm{~km}$ of a respondent increases the probability of internet adoption by $1.2 \%$, which corresponds to an increase in the likelihood of adoption from around $12 \%$ to around $13.2 \%$ in an average respondent. Also, in the full specification in column 11, the coefficients on the control variables are consistent with intuition and they are all statistically significant at the $1 \%$-level. For instance, older and unemployed respondents are less likely to adopt broadband services, whereas higher income earners, more educated individuals and urban dwellers are more likely to adopt the internet. For religion, being a Christian increases the probability of adoption. The positive coefficient on the male gender variable is consistent with the patriarchal nature of the Nigerian society, which indicates that the men are more likely to adopt internet services, perhaps reflecting the stronger socioeconomic power of the male gender. Interestingly, in terms of the magnitude of the coefficients, we find age and gender to have the greatest effect on broadband adoption, with both coefficients indicating $11 \%$ and $5 \%$ positive impact on the probability of adoption, respectively. The age coefficient lends weight to our opening arguments on the implications of broadband adoption for the participation of the large projected youth population of Nigeria in an increasingly digitalized global economy in the future. For all the specifications in Table 2, the results also show that individuals in areas with a higher concentration of network infrastructure are more likely to adopt and use broadband services.

\section{Concluding Remarks and Next Steps}

This paper presents first-stage results showing factors that influence internet adoption in Nigeria. Using geo-referenced information of an inventory of broadband network infrastructure, we employ a more appropriate micro-spatial measure of internet infrastructure based on $3 \mathrm{G} / 4 \mathrm{G}$ network equipment at the local level alongside a range of explanatory variables to explain internet adoption in Nigeria. In general, the results obtained are economically important, and they can help explain the adoption patterns of broadband services particularly when network infrastructure effects are likely to play an important role in driving internet penetration. For instance, in many regions across developing countries, network coverage is usually the first modern technology of any kind (Aker and Mbiti 2010). Hence, we would argue that the failure to control for this network infrastructure effect in the study of broadband adoption across developing countries could well result in significant omitted variable bias. Furthermore, the network infrastructure effect may also explain the nuances embodied in the varied adoption of broadband services across different regions, given that the quality of service (QoS) and user experience may well depend on the diffusion and reliability of the underlying network infrastructure.

Although the first-stage results presented in this paper revealed preliminary drivers of internet adoption, they also provide interesting avenues for further study which we aim to explore in subsequent analysis of the dataset. In the first place, the significant urban variable shows that there are likely to be regional differences with regards to the 
factors that influence internet adoption in Nigeria. Given that Nigeria has one of the largest rural population in Africa (World Bank 2018), we expect that further analysis testing the relationships in this study across rural and urban dwellers, will contribute significantly to the policy debate on bridging the urban-rural internet divide in Nigeria. Further, having microeconomic information that is representative of the national population of the type used in this research, permits clear visualization of the digital divide as an additional form of inequality that can hinder access to other internet-reliant technologies. For instance, the telecommunications sector in Nigeria is currently undergoing several policy changes, one of which is the granting of mobile money licenses to mobile network operators. Therefore, it is earmarked that further analysis with our data will explore diffusion constraints for other technologies covered in the survey data and how usage patterns might vary in different parts of the country. We hope that the results of these avenues of research will provide new insights that contribute to both policy and research.

Acknowledgements. The authors also gratefully acknowledge the support of Africa's leading mobile operator MTN, for providing the market survey and operator data employed in this study. Special thanks to the staff of the Business Intelligence and Research Departments. We also like to thank participants at various seminars and workshops for their helpful comments. The usual disclaimer applies.

\section{Appendix Section}

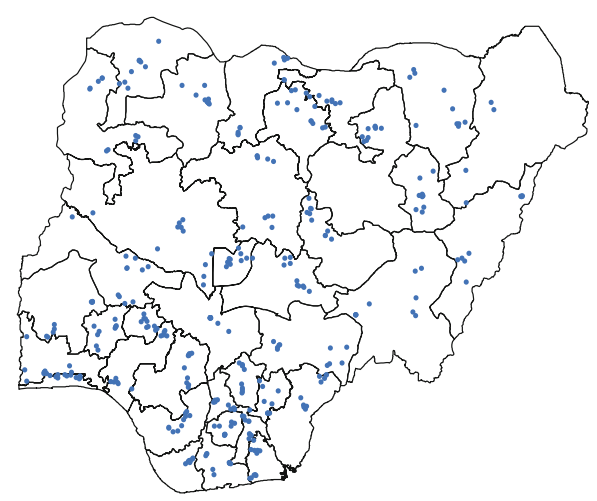

Fig. A. Nigerian map showing surveyed areas

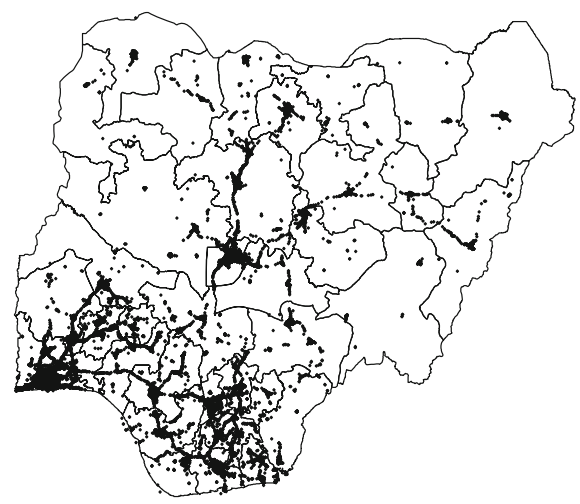

Fig. B. Tower sites in Nigeria (source: OpenCellID data) 


\section{References}

Afolayan, A., Plant, E., White, G.R., Jones, P., Beynon-Davies, P.: Information technology usage in SMEs in a developing economy. Strategic Change 24(5), 483-498 (2015)

Aker, J.C., Mbiti, I.M.: Mobile phones and economic development in Africa. J. Econ. Perspect. 24(3), 207-232 (2010)

Avgerou, C.: Information systems in developing countries: a critical research review. J. Inf. Technol. 23(3), 133-146 (2008)

Beard, T.R., Ford, G.S., Saba, R.P., Seals Jr., R.A.: Internet use and job search. Telecommun. Policy 36(4), 260-273 (2012)

Business Monitor International (BMI): Nigeria Telecommunications Report, Q2 (2018). http:// www.bmiresearch.com. Accessed 27 Dec 2018

Bulte, E., Lensink, R., Vu, N.: Gender training and female empowerment: experimental evidence from Vietnam. Econ. Lett. 145, 117-119 (2016)

Buys, P., Dasgupta, S., Thomas, T.S., Wheeler, D.: Determinants of a digital divide in SubSaharan Africa: a spatial econometric analysis of cell phone coverage. World Dev. 37(9), 1494-1505 (2009)

Cardona, M., Kretschmer, T., Strobel, T.: ICT and productivity: conclusions from the empirical literature. Inf. Econ. Policy 25(3), 109-125 (2013)

Chinn, M.D., Fairlie, R.W.: The determinants of the global digital divide: a cross-country analysis of computer and internet penetration. Oxford Econ. Pap. 59(1), 16-44 (2007)

Chinn, M.D., Fairlie, R.W.: ICT use in the developing world: an analysis of differences in computer and internet penetration. Rev. Int. Econ. 18(1), 153-167 (2010)

Czernich, N., Falck, O., Kretschmer, T., Woessmann, L.: Broadband infrastructure and economic growth. Econ. J. 121(552), 505-532 (2011)

Dasgupta, S., Lall, S., Wheeler, D.: Policy reform, economic growth and the digital divide. Oxford Dev. Stud. 33(2), 229-243 (2005)

DeStefano, T., Kneller, R., Timmis, J.: Broadband infrastructure, ICT use and firm performance: evidence for UK firms. J. Econ. Behav. Organ. 155, 110-139 (2018)

Feng, G.C.L.: Determinants of internet diffusion: a focus on China. Technol. Forecast. Soc. Change 100, 176-185 (2015)

Fungáčová, Z., Hasan, I., Weill, L.: Trust in banks. J. Econ. Behav. Organ. 157, 452-476 (2017)

Galperin, H., Ruzzier, C.A.: Price elasticity of demand for broadband: evidence from Latin America and the Caribbean. Telecommun. Policy 37(6-7), 429-438 (2013)

Greenstein, S.M., Spiller, P.T.: Modern telecommunications infrastructure and economic activity: an empirical investigation. Ind. Corporate Change 4(4), 647-665 (1995)

Hodler, R., Raschky, P.A.: Ethnic politics and the diffusion of mobile technology in Africa. Econ. Lett. 159, 78-81 (2017)

Hübler, M., Hartje, R.: Are smartphones smart for economic development? Econ. Lett. 141, 130133 (2016)

Liang, P., Guo, S.: Social interaction, internet access and stock market participation -an empirical study in China. J. Comp. Econ. 43(4), 883-901 (2015)

Lin, M.S., Wu, F.S.: Identifying the determinants of broadband adoption by diffusion stage in OECD countries. Telecommun. Policy 37(4-5), 241-251 (2013)

Liu, M.C., San, G.: Social learning and digital divides: a case study of internet technology diffusion. Kyklos 59(2), 307-321 (2006)

Neto, I., Niang, C., Ampah, M.: Fostering pro-competitive regional connectivity in Sub-Saharan Africa. Global ICT Department, The World Bank, Washington, DC (2005) 
Oyelaran-Oyeyinka, B., Lal, K.: Internet diffusion in sub-Saharan Africa: a cross-country analysis. Telecommun. Policy 29(7), 507-527 (2005)

Paunov, C., Rollo, V.: Has the Internet fostered inclusive innovation in the developing world? World Dev. 78, 587-609 (2016)

Roller, L.H., Waverman, L.: Telecommunications infrastructure and economic development: a simultaneous approach. Am. Econ. Rev. 91(4), 909-923 (2001)

The Economist: Building a digital Nigeria, Economist Intelligence Unit (2016)

Tranos, E.: The causal effect of the internet infrastructure on the economic development of European city regions. Spatial Econ. Anal. 7(3), 319-337 (2012)

World Bank: Rural population - Nigeria (2018). https://data.worldbank.org/indicator/SP.RUR. TOTL?locations=NG. Accessed 22 Oct 2019 